\title{
Factors associated with institutional delivery practice among women in pastoral community of Dubti district, Afar region, Northeast Ethiopia: a community-based cross-sectional study
}

\author{
Wassie Sadik ${ }^{1}$ Alemayehu Bayray ${ }^{2}$, Ayal Debie ${ }^{3}$ and Tsegaye Gebremedhin ${ }^{3 *}$
}

\begin{abstract}
Background: Eighty-five percent of the global burden of maternal mortality was covered by Sub-Saharan Africa. Ethiopia is a major contributor to the death of mothers with a maternal mortality ratio of 676 per 100,000 live births. Only $10 \%$ of deliveries in Ethiopia were at health facility with the least (6.4\%) in the Afar region. However, there is limited evidence about factors of institutional delivery in the study area. Thus, this study aimed to assess the magnitude and associated factors of institutional delivery practice among women in the pastoral community of Dubti district, Northeast Ethiopia.

Methods: A community based cross-sectional study was conducted from April to May 2016, in the pastoral community of Dubti district. A total of 381 women were selected using systematic sampling technique and interviewed using a standardized structured questionnaire. Binary logistic regression analysis was computed. In the final multivariable logistic regression analysis adjusted odds ratio (AOR) with 95\% confidence interval (Cl) was used to declare the factors associated with institutional delivery.

Results: This study revealed that $35.2 \%$ (95\% Cl: 30.5-40.1) of women were delivered at the health facility. Women who had travelled less than an hour to reach the nearest health facilities (AOR: 4.90, 95\% Cl: 2.62-9.18), attending antenatal care (AOR: 2.50, 95\% Cl:1.48-4.23), previous history of stillbirth (AOR: 4.34, 95\% Cl: 1.78-10.58), good knowledge (AOR: 2.09, 95\% Cl:1.23-3.56), and husband involved in decision making on delivery place (AOR: 4.42, 95\% Cl: 1.98-9.90) were the factors associated with institutional delivery practice.

Conclusions: The overall institutional delivery practices in the study area was low as compared to the national level. This low practice of institutional delivery was contributed by residing far from the facility, does not received antenatal care, and having low awareness about ANC follow up and institutional delivery services. Therefore, strengthening the accessibility of health facility to nearby mothers resided, antenatal care services, and awareness creation provision at the community level for pregnant women in the pastoral community can improve institutional delivery practice.
\end{abstract}

Keywords: Institutional delivery, Practice, Pastoral community, Dubti, Ethiopia

\footnotetext{
* Correspondence: tsegishg27@gmail.com

${ }^{3}$ Department of Health Systems and Policy, Institute of Public Health, College

of Medicine and Health Sciences, University of Gondar, Po. Box: 196, Gondar,

Ethiopia

Full list of author information is available at the end of the article
}

(c) The Author(s). 2019 Open Access This article is distributed under the terms of the Creative Commons Attribution 4.0 International License (http://creativecommons.org/licenses/by/4.0/), which permits unrestricted use, distribution, and reproduction in any medium, provided you give appropriate credit to the original author(s) and the source, provide a link to the Creative Commons license, and indicate if changes were made. The Creative Commons Public Domain Dedication waiver (http://creativecommons.org/publicdomain/zero/1.0/) applies to the data made available in this article, unless otherwise stated. 


\section{Plain English summary}

Institutional delivery is the corner stone to reduce maternal death and improve neonatal health. The practice of institutional delivery services utilization is very low in the pastoral community of Dubti district. One of the major contributors to high maternal deaths in Ethiopia was low institutional delivery. Accordingly, low practice of institutional delivery in the study area could also affect the health status and wellbeing of the newborn. Moreover, there are number of factors that hinder institutional delivery service utilization in the community. Those factors might be linked with women's cultural, social, and personal factors.

In the study area, nothing is known about the factors that affect institutional delivery service practices. Therefore, this study aimed to identify the factors that hinder institutional delivery service practices among women who gave birth in the last 12 months. Structured interviewer-administered questionnaire was used for interviewing the women. Accordingly, women who had resided away from the health facility might not receiving follow up and did not face any complication during the recent pregnancy. Additionally, they did not know the benefit of institutional delivery service and had no any involvement of their husband on decision of delivery place were factors associated with institutional delivery utilization of the women.

\section{Background}

Childbirth is an essential affair in the lives of families and the building of communities. Almost all fatal outcomes and disabling result of women during childbirth can be prevented and much of the suffering can be alleviated with skilled and responsive care at delivery and during the postnatal period [1]. An estimated 287, 000 maternal deaths occurred worldwide in 2011. From this, Sub-Saharan Africa accounts for 56\% and Southern Asia $29 \%$ which is constituted for $85 \%$ of the global burden of maternal death [2]. Globally, $80 \%$ of all maternal deaths occurred due to direct causes which are hemorrhage, hypertensive disorders, infections, unsafe abortion, sepsis, and obstructed labor [3].

Complications during pregnancy and childbirth are the leading causes of death among adolescent girls aged 15-19 years in low and middle-income countries resulting in thousands of deaths each year [4, 5]. Maternal death is high particularly in settings with high home delivery, and areas with poor civil registration systems to identify the correct causes of maternal death [6]. Ethiopia was one of the leading contributors to maternal deaths in Sub-Saharan African countries. With maternal mortality ratio (MMR) of 676 per 100,000 live births in 2011 [7]. The Ethiopian Mini Demographic and Health Survey (EMDHS), 2014 report indicated that institutional delivery in Afar region was 6.4\% which was the lowest among the nine regions in Ethiopia [8]. Furthermore, 19\% of women had four or more antenatal care (ANC) visits during their recent pregnancy and only $10 \%$ of pregnant women delivered at the health facility [8] which indicates low utilization of modern maternal health care.

Every pregnancy faces a risk which may not always be detected through the risk assessment approach during ANC follow up. However, the majority of deaths due to obstetric complications are preventable and the best way to assure a safe and successful delivery outcome was through attending institutional delivery with a skilled birth attendant. But it was not well known why the majority of pastoral pregnant women did not deliver at the health institution. Therefore, this study was designed to assess the magnitude and associated factors of institutional delivery practice among women who gave birth in the last 12 months in the pastoral community of Dubti district, Afar region, Northeast Ethiopia.

\section{Methods \\ Study design and setting}

A community based cross-sectional study design was conducted at Dubti district in Afar Regional State from April to May, 2016. The district has 14 (2 urban and 12 rural) kebeles (the smallest administrative unit). It has also 1 referral hospital, 3 health centers, and 10 Health posts. The source population were all reproductive age group women who gave birth within the last 12 months in Dubti district, whereas the study population was all reproductive age group women who gave birth within the last 12 months in the selected kebeles of Dubti district.

\section{Sample size and sampling techniques}

The sample size was calculated by using both single and double population proportion formula. The sample size for the first objective was calculated by using single population proportion formula with an assumption of proportion $(\mathrm{P})=16.7 \%$ [9], 4\% margin of error (d), 95\% confidence level, and $10 \%$ non-response rate. $N=\left(\mathrm{Z}_{\alpha / 2}\right)$ [2]"P $(1-\mathrm{P}) /(\mathrm{d})[2]=(1.96)^{2}(0.167)(0.833) /(0.04)[2]=$ 334. The final sample size for the first objective was 368 .

Additionally, the sample size for the second objective was calculated by using double population proportion formula considering $80 \%$ power, $95 \%$ confidence level, $10 \%$ non-response rate. The proportion of institutional delivery among ANC attended women (30.7\%) [10] and among urban residents (22.4\%) [11] among women who gave birth at health facility had taken for sample size calculation. Then the calculated sample size by using were 376 and 383, respectively. The calculated sample size for the second factor in the double population proportion formula was higher than others. Therefore, for maintaining 
sample size adequacy we used 383 which was the largest. Then, one urban and three rural kebeles among 14 kebeles of the district were selected using simple random lottery method. The sample was proportionally allocated to each selected kebeles based on their total estimated birth rate. Proportionate stratified systematic sampling technique was used to select the participants. The first woman was selected through simple random lottery method. Then, every other household woman starting from the first selected household were used to select the study participant. Accordingly, when two or more women who had lived together within a household had got, one of them was selected through simple random lottery method.

\section{Measurement and variables}

A woman who gave birth for their last child at health institution for the last 1 year were considered as institutional delivery. Knowledge of women was measured by using 8 item questions each containing $(0=$ No and $1=$ yes) alternatives and those women who scored $60 \%$ and above the total knowledge measuring score were considered as having good knowledge. Accordingly, the attitude of women towards institutional delivery was measured by using 6 item questions each containing $(1=$ strongly disagree, $2=$ disagree, $3=$ neutral, $4=$ agree, and $5=$ strongly agree) alternatives and those women who scored $60 \%$ and above the total attitude measuring score were considered as having a favorable attitude.

\section{Data collection tools and procedures}

An interviewer-administered structured questionnaire was adapted from different studies [11-14] and used to collect data among women aged 15-49 years who gave birth in the last 12 months. The questionnaire was initially developed in English and translated into local Afaraff language and finally back to English in order to ensure its consistency. Four diploma clinical nurses for data collectors and two bachelor degree nurses for supervisors were recruited. The training was given for 1 day on the basic techniques of data collection and pretesting was conducted on 19 women at Logia district (neighboring district which has similar population characteristics and infrastructure to Dubti district) before the actual data collection. Finally, all findings from the pre-test were incorporated into the final questionnaire. During data collection, supervisors have checked the data for accuracy, consistency, and completeness on a daily basis.

\section{Data management and analysis}

Data were cleaned, coded and entered to EPI info version 3.5.1 and exported to STATA version 13 software for analysis. Frequencies and percentage of variables were presented using tables and graphs. Bivariable and multivariable logistic regression analysis were conducted and those predictor variables with $P$-value less than 0.2 in the bivariable logistic regression analysis were entered to multivariable logistic regression analysis. Adjusted Odds Ratio (AOR) with 95\% CI was used to identify the strength and associated factors with the outcome variable. Those independent variables with a $P$-value of less than 0.05 during multivariable logistic regression analysis were considered as significantly associated with the outcome variable.

\section{Results}

\section{Socio-demographic and economic characteristics}

A total of 381 reproductive age group women who gave birth in the last 12 months had participated in the study. The mean age $( \pm$ SD) of the study participants was 25.7 $( \pm 5.3)$ years. More than three-fourth (86.3\%) of the participants were Muslim followers. Out of all participants, 91.6\% were married. Furthermore, $62.9 \%$ of the participants' occupation was staying at home (housewives) and $47.8 \%$ of their husband's occupation was pastoralist. Accordingly, $68.2 \%$ of participants were Afar in their ethnicity and $64.3 \%$ were not educated. About $23.9 \%$ of women had less than 500 Ethiopian birr (\$17.8) monthly household income (Table 1).

\section{Obstetric history of the study participants}

In this study, $42.7 \%$ of women had attended at least one antenatal visit during their recent pregnancy. Of those, only $23.3 \%$ of them had four or more antenatal visits and more than half (55.2\%) had been started their first antenatal visit during their third trimester. More than 20 $\%$ of women had five or more history of pregnancy and delivery. Similarly, nearly 20 and $10 \%$ of women had previous history of abortion and stillbirth, respectively. Furthermore, 41.7 and $46.2 \%$ of women had good knowledge and favorable attitude towards institutional delivery, correspondingly (Table 2).

\section{Institutional delivery practice of participants}

Overall 35.2\% (95\% CI: 30.5-40.1\%) of women had gave birth at the health facility. From women who gave birth at the health facility, for $45.5 \%$ women who had gave birth at health facility had been attended by midwiferies followed by nurses $25.4 \%$. Forty six percent of the husband of women were involved in the decision of delivery place. On top of this, $20.6 \%$ of women reported that they gave birth at home since the health facilities were too far from their home. About one-fourth (24.3\%) of women who had delivered at home were attended by their mother in law. Twenty percent of women who had delivered at health facility reported that institutional delivery was one of the major factors that contribute for saving maternal life. About $32 \%$ of women had faced 
Table 1 Socio-demographic and economic characteristics of participants in Dubti district, Afar region, Northeast Ethiopia, 2016

\begin{tabular}{|c|c|c|c|}
\hline Variables & Category & $\begin{array}{l}\text { Frequency } \\
\text { (n) }\end{array}$ & $\begin{array}{l}\text { Percent } \\
\text { (\%) }\end{array}$ \\
\hline \multirow[t]{5}{*}{ Age in years } & $15-19$ & 45 & 11.81 \\
\hline & $20-24$ & 133 & 34.91 \\
\hline & $25-29$ & 111 & 29.13 \\
\hline & $30-34$ & 65 & 17.06 \\
\hline & $>35$ & 27 & 7.09 \\
\hline \multirow[t]{3}{*}{ Marital status } & Married & 349 & 91.60 \\
\hline & Divorced & 19 & 4.99 \\
\hline & Single & 13 & 3.41 \\
\hline \multirow[t]{2}{*}{ Residence } & Urban & 96 & 25.20 \\
\hline & Rural & 285 & 74.80 \\
\hline \multirow{4}{*}{$\begin{array}{l}\text { Occupation of } \\
\text { women }\end{array}$} & Pastoral & 70 & 18.37 \\
\hline & Merchant & 37 & 9.71 \\
\hline & $\begin{array}{l}\text { Government } \\
\text { employee }\end{array}$ & 34 & 8.92 \\
\hline & Stay at home & 240 & 62.99 \\
\hline \multirow[t]{2}{*}{ Religion } & Christian & 52 & 13.65 \\
\hline & Muslim & 329 & 86.35 \\
\hline \multirow[t]{4}{*}{ Ethnicity } & Afar & 260 & 68.24 \\
\hline & Oromo & 13 & 3.41 \\
\hline & Amhara & 94 & 24.67 \\
\hline & Tigray & 14 & 3.68 \\
\hline \multirow[t]{3}{*}{ Monthly income } & $<500$ ETB & 91 & 23.88 \\
\hline & 500-1000 ETB & 160 & 41.99 \\
\hline & $>1000$ ETB & 130 & 34.12 \\
\hline \multirow[t]{5}{*}{ Women literacy status } & Not educated & 245 & 64.30 \\
\hline & $\begin{array}{l}\text { Able to read and } \\
\text { write }\end{array}$ & 48 & 12.60 \\
\hline & Primary education & 52 & 13.65 \\
\hline & Secondary education & 13 & 3.41 \\
\hline & Higher education & 23 & 6.04 \\
\hline \multirow{5}{*}{$\begin{array}{l}\text { Husband literacy } \\
\text { status }\end{array}$} & Not educated & 150 & 42.98 \\
\hline & $\begin{array}{l}\text { Able to read and } \\
\text { write }\end{array}$ & 104 & 29.80 \\
\hline & Primary education & 29 & 8.31 \\
\hline & Secondary education & 37 & 10.60 \\
\hline & Higher education & 29 & 8.31 \\
\hline \multirow{4}{*}{$\begin{array}{l}\text { Occupation of } \\
\text { husband }\end{array}$} & Farmer & 58 & 16.62 \\
\hline & Pastoralist & 167 & 47.85 \\
\hline & Merchant & 79 & 22.64 \\
\hline & $\begin{array}{l}\text { Government } \\
\text { employee }\end{array}$ & 45 & 12.89 \\
\hline
\end{tabular}

ETB Ethiopian Birr
Table 2 Knowledge of women on institutional delivery in Dubti district, Afar region, Northeast, Ethiopia, $2016(n=381)$

\begin{tabular}{|c|c|c|c|}
\hline Variables & Category & $\begin{array}{l}\text { Frequency } \\
\text { (n) }\end{array}$ & $\begin{array}{l}\text { Percent } \\
(\%)\end{array}$ \\
\hline \multirow[t]{2}{*}{ Attend ANC } & No & 218 & 57.22 \\
\hline & Yes & 163 & 42.78 \\
\hline \multirow{3}{*}{$\begin{array}{l}\text { Number of ANC visit } \\
(n=163)\end{array}$} & One & 71 & 43.56 \\
\hline & Two-three & 54 & 33.13 \\
\hline & $>$ Four & 38 & 23.31 \\
\hline \multirow{3}{*}{$\begin{array}{l}\text { Gestational age during } \\
1 \text { st visit }(n=163)\end{array}$} & 1st trimester & 33 & 20.25 \\
\hline & 2nd trimester & 40 & 24.54 \\
\hline & 3rd trimester & 90 & 55.21 \\
\hline \multirow[t]{3}{*}{ Gravidity } & One & 60 & 15.75 \\
\hline & Two to four & 299 & 60.10 \\
\hline & $>$ Five & 92 & 24.15 \\
\hline \multirow[t]{3}{*}{ Parity } & One & 92 & 24.15 \\
\hline & Two - four & 205 & 53.81 \\
\hline & $>$ five & 84 & 22.05 \\
\hline \multirow{2}{*}{$\begin{array}{l}\text { Number of under five } \\
\text { children }\end{array}$} & One & 93 & 24.41 \\
\hline & $>$ Two & 288 & 75.59 \\
\hline \multirow{3}{*}{$\begin{array}{l}\text { Total family size in a } \\
\text { household }\end{array}$} & $<$ Three & 98 & 25.72 \\
\hline & Three to four & 82 & 21.52 \\
\hline & $>$ five & 201 & 52.76 \\
\hline \multirow[t]{2}{*}{ History of abortion } & No & 307 & 80.58 \\
\hline & Yes & 74 & 19.42 \\
\hline \multirow{2}{*}{$\begin{array}{l}\text { Frequency of abortion } \\
(n=74)\end{array}$} & One & 68 & 91.89 \\
\hline & $>$ Two & 6 & 8.11 \\
\hline \multirow[t]{2}{*}{ History of still birth } & No & 344 & 90.29 \\
\hline & Yes & 37 & 9.71 \\
\hline \multirow{2}{*}{$\begin{array}{l}\text { Frequency of still birth } \\
(n=37)\end{array}$} & One & 32 & 86.49 \\
\hline & $>$ Two & 5 & 13.51 \\
\hline \multirow[t]{2}{*}{ Knowledge of women } & Good & 159 & 41.73 \\
\hline & Poor & 222 & 58.27 \\
\hline \multirow[t]{2}{*}{ Attitude of women } & Favorable & 176 & 46.19 \\
\hline & Unfavorable & 205 & 53.81 \\
\hline \multirow[t]{2}{*}{ History of difficult labor } & No & 264 & 69.29 \\
\hline & Yes & 117 & 30.71 \\
\hline \multirow[t]{2}{*}{ Travel time to reach the HF } & $\leq 1 \mathrm{~h}$ & 205 & 53.81 \\
\hline & $>1 \mathrm{~h}$ & 176 & 46.19 \\
\hline \multirow[t]{2}{*}{$\begin{array}{l}\text { Source of information } \\
(n=362)\end{array}$} & $\begin{array}{l}\text { Health } \\
\text { workers }\end{array}$ & 285 & 78.73 \\
\hline & Mass media & 77 & 21.27 \\
\hline
\end{tabular}

HF Health Facility

complication during their recent birth. Nearly two-thirds (65.3\%) of women had excessive vaginal bleeding among those who had faced complications (Table 3). 
Table 3 Recent institutional delivery practice of mothers in Dubti district, Afar region, Northeast Ethiopia, $2016(n=381)$

\begin{tabular}{|c|c|c|c|}
\hline Variables & Category & Frequency (n) & Percent (\%) \\
\hline \multirow[t]{2}{*}{ Institutional delivery } & No & 247 & 64.8 \\
\hline & Yes & 134 & 35.2 \\
\hline \multirow[t]{4}{*}{ Who assisted the delivery at HF? $(n=134)$} & Nurse & 34 & 25.37 \\
\hline & Health officer & 12 & 8.96 \\
\hline & Midwifery & 61 & 45.52 \\
\hline & Doctor & 27 & 20.15 \\
\hline \multirow[t]{3}{*}{ Who was decision-maker for the place of delivery? } & Herself & 66 & 17.32 \\
\hline & Husband & 175 & 45.93 \\
\hline & Other relatives & 140 & 36.75 \\
\hline \multirow[t]{5}{*}{ Who assisted home delivery? $(n=247)$} & Her mother & 46 & 18.62 \\
\hline & Mother in law & 60 & 24.29 \\
\hline & TTBA & 51 & 20.65 \\
\hline & Neighbor & 54 & 21.87 \\
\hline & Health Extension Workers & 36 & 14.57 \\
\hline \multirow[t]{3}{*}{ Reasons for HF delivery $(n=134)$} & Received health education & 38 & 28.36 \\
\hline & Good service & 69 & 51.49 \\
\hline & Save mothers life & 27 & 20.15 \\
\hline \multirow{2}{*}{$\begin{array}{l}\text { Have you faced any complication during } \\
\text { your recent labor and delivery (381) }\end{array}$} & Yes & 121 & 31.8 \\
\hline & No & 260 & 68.2 \\
\hline \multirow{4}{*}{$\begin{array}{l}\text { Type of complication that faced during } \\
\text { labor and delivery? }(n=121)\end{array}$} & Excessive Vx bleeding & 79 & 65.29 \\
\hline & Retained placenta & 8 & 6.61 \\
\hline & Prolonged labor & 22 & 18.18 \\
\hline & Mal presentation & 12 & 9.92 \\
\hline \multirow[t]{8}{*}{ Reasons for home delivery $(n=247)$} & Fast labor & 26 & 10.53 \\
\hline & Transport problem & 45 & 18.22 \\
\hline & Health facility far & 51 & 20.65 \\
\hline & Husband refuse & 40 & 16.19 \\
\hline & Fear of user fee & 21 & 8.50 \\
\hline & Poor service provision & 14 & 5.67 \\
\hline & Feel shame & 21 & 8.50 \\
\hline & Others & 29 & 11.74 \\
\hline
\end{tabular}

\section{Factors associated with institutional delivery}

In the multivariable logistic regression analysis, women traveling within an hour or less far from the nearby health facilities were 4.90 times more likely to deliver at health institution than women traveling more than an hour (AOR: 4.90, 95\% CI: 2.62-9.18). Women who attend ANC during their recent pregnancy were 2.50 times more likely to attend institutional delivery as compared to their counterparts (AOR: 2.50 , 95\% CI: $1.48-$ 4.23). Those mothers having a history of stillbirths were 4.34 times more likely attending intuitional delivery compared to those mothers who had no history of stillbirth (AOR: 4.34, 95\% CI: 1.78-10.58). Women having good knowledge about delivery and pregnancy-related complications and services were 2.09 times more likely to deliver at a health facility than women who had poor knowledge (AOR: 2.09, 95\% CI: 1.23-3.56). Moreover, women's whose husband involved in decision making on the place of delivery were 4.42 times more likely attending institutional delivery compared to women who decide their place of delivery by themselves (AOR: 4.42, 95\% CI: 1.98-9.90) (Table 4).

\section{Discussion}

Having safe and skilled delivery is one of the cornerstones able to reduce maternal death and improve child health. This study was designed to assess magnitude and determinants of institutional delivery service utilization 
Table 4 Logistic regression analysis on factors associated with institutional delivery practice in Dubti district Afar Region, Northeast, Ethiopia, $2016(n=381)$

\begin{tabular}{|c|c|c|c|c|c|}
\hline \multirow[t]{2}{*}{ Variables } & \multirow[t]{2}{*}{ Category } & \multicolumn{2}{|c|}{ Institutional Delivery } & \multirow[t]{2}{*}{ COR $(95 \% \mathrm{Cl})$} & \multirow[t]{2}{*}{ AOR (95\% CI) } \\
\hline & & Yes & No & & \\
\hline \multirow[t]{5}{*}{ Age in years } & $15-19$ & 11 & 34 & 1 & 1 \\
\hline & $20-24$ & 42 & 91 & $1.43(0.66-3.09)$ & $1.73(0.67-4.46)$ \\
\hline & $25-29$ & 47 & 64 & $2.27(1.04-4.94)$ & $2.32(0.80-6.72)$ \\
\hline & $30-34$ & 26 & 39 & $2.04(0.89-4.78)$ & $1.74(0.50-6.04)$ \\
\hline & $>35$ & 8 & 19 & $1.30(0.45-3.79)$ & $1.20(0.24-6.14)$ \\
\hline \multirow[t]{2}{*}{ Residence } & Urban & 49 & 47 & $2.45(1.53-3.94)$ & $1.16(0.60-2.23)$ \\
\hline & Rural & 85 & 200 & 1 & 1 \\
\hline \multirow[t]{5}{*}{ Women literacy status } & Not educated & 80 & 165 & 1 & 1 \\
\hline & Able to read \& write & 18 & 30 & $1.24(0.65-2.35)$ & $1.45(0.67-3.12)$ \\
\hline & Primary & 20 & 32 & $1.29(0.69-2.39)$ & $1.34(0.62-2.88)$ \\
\hline & Secondary & 5 & 8 & $1.28(0.41-4.07)$ & $2.62(0.55-12.41)$ \\
\hline & Higher & 11 & 12 & $1.89(0.80-4.47)$ & $4.33(0.83-22.61)$ \\
\hline \multirow[t]{2}{*}{ Travel time to reach the HF } & $<1 \mathrm{~h}$ & 103 & 102 & $4.72(2.94-7.59)$ & $4.90(2.62-9.18) *$ \\
\hline & $>1 \mathrm{hs}$ & 31 & 145 & 1 & 1 \\
\hline \multirow[t]{2}{*}{ ANC visit at least once for their recent pregnancy } & No & 56 & 162 & 1 & 1 \\
\hline & Yes & 78 & 85 & $2.65(1.72-4.09)$ & $2.50(1.48-4.23) *$ \\
\hline \multirow[t]{3}{*}{ Gravidity } & One & 15 & 45 & 1 & 1 \\
\hline & Two to Four & 82 & 147 & $1.67(0.88-3.19)$ & $2.18(0.67-7.07)$ \\
\hline & $>$ Five & 37 & 55 & $2.02(0.98-4.14)$ & $6.56(0.76-56.87)$ \\
\hline \multirow[t]{2}{*}{ History of abortion } & No & 107 & 200 & 1 & 1 \\
\hline & Yes & 27 & 47 & $1.07(0.63-1.82)$ & $1.14(0.47-1.89)$ \\
\hline \multirow[t]{2}{*}{ History of stillbirth } & No & 112 & 232 & 1 & 1 \\
\hline & Yes & 22 & 15 & $3.04(1.52-6.08)$ & $4.34(1.78-10.58) *$ \\
\hline \multirow[t]{2}{*}{ Knowledge of women } & Good & 70 & 89 & $1.94(1.27-2.98)$ & $2.09(1.23-3.56) *$ \\
\hline & Poor & 64 & 158 & 1 & 1 \\
\hline \multirow[t]{2}{*}{ Attitude of women } & Favorable & 69 & 107 & $1.39(0.91-2.12)$ & $1.22(0.73-2.05)$ \\
\hline & Unfavorable & 65 & 140 & 1 & 1 \\
\hline \multirow[t]{3}{*}{ Decision on delivery place } & Herself & 12 & 54 & 1 & 1 \\
\hline & Husband & 80 & 95 & $3.79(1.90-7.57)$ & $4.42(1.98-9.90) *$ \\
\hline & Other relatives & 42 & 98 & $1.93(0.94-3.97)$ & $2.00(0.87-4.60)$ \\
\hline
\end{tabular}

*statistically significant at $p$-value $<0.05$

among women who gave birth in the last 12 months in the pastoral community of Dubti district Northeast, Ethiopia. About 35.2\% (95\% CI: 30.4-40) of women delivered at the health facility. This result was in line with the studies conducted in Dembecha district, Northwest Ethiopia shows that $34 \%$ of mothers delivered at the health facility and in Ghana shows that $37.5 \%$ of women delivered at health facility $[15,16]$. However, this study finding was higher than a study conducted in Wukro and Butajira districts 25\% [10], Sekela 12.1\% [14], Munisa 12.3\% [11], Dodota 18.2\% [17], mini EDHS 2014 report in Afar region $6.4 \%$ and nationally $16 \%$ [18], EDHS 2016 report of Somali region 18\% and Afar region
$15 \%$, and nationally in Ethiopia 26\% [19], nomads of Sudan 20\% [20]. But, this result was lower than a study conducted in Woldia, Ethiopia 48.3\% [21], Bahir Dar, Ethiopia 78.8\% [13], Tigray Region 59\%, Dire Dawa 59\%, and Addis Ababa 79\% [7], and Tanzania 74.5\% [12]. The possible explanation for this variation was due to the difference in the study area, design and period, and also the economical variation of the study participants.

Institutional delivery service utilization was 2.5 times higher among women attended ANC during their recent pregnancy as compared to women who did not attend ANC. This finding is consistent with studies conducted in Sekela and Goba district $[14,22]$. This might be due to the 
information on the importance of institutional delivery they got during their follow up could influence their decision to deliver at health facilities.

Mothers who were traveling an hour or less to reach the nearest health facility were 4.9 times more likely to attend institutional delivery as compared to mothers who were traveling more than an hour to reach the nearest health facility. This finding was consistent with a study conducted in western Ethiopia and Dembecha district [16, 23].

This might be due to mothers who were resided nearby health institutions might have different access to maternal health services such as maternal servicerelated health education. In addition, mothers had no shortage of transportation access to attend their deliveries at health facilities at any time whether their labor starts. Furthermore, in the pastoral community most of their husbands and adult male family members were seasonally moving from place to place to fed and to get water for their cattle's and those mothers who were in labor during this time and resided away from health facility had no support to take them to health facilities.

Those mothers who had the previous history of stillbirth were 4.34 times more likely to attend institutional delivery as compared to mothers who had no history of still birth. This finding is in contrast with finding in Dembecha district which mother who had a history of abortion in their life time were less likely to received institutional delivery [16]. The possible explanation for our finding might be due to mothers who had the previous history of stillbirth might increase their concern for the newborn healthy outcome and other complications for the next delivery. This could enhance their probability of attending continuum of maternal health care services; attending ANC and attending ANC services would also improve their utilization of institutional delivery services.

Women who had good knowledge about pregnancy and delivery related services and complications were 2.09 times more likely to attend institutional delivery as compared to women who had poor knowledge. This finding was in line with the study conducted at Sekela district and western Ethiopia [14, 23]. This might be due to knowledgeable women had high probability of capturing the benefits of attending institutional delivery during their ANC visits counseling and other maternal healthrelated education. The other possible explanation might be mothers having good knowledge relatively may not be affected by traditional malpractices. For instance; in the pastoral community those mothers who delivered at the home considered as the hero of that community, so mothers had good knowledge about the benefits of institutional delivery does not accept the traditional malpractice. In addition, knowledgeable mothers had also a great influence on their husbands and/or other relatives to take them to a health facility as soon as labor was started.

Women whose husband involved during the decision of delivery place was 4.42 times more likely to deliver at a health facility than women's husband who were not involved. This study was consistent with the study conducted at Dodota district [17]. This might be due to the dominancy of a husband during decision made in the pastoral community which might increase institutional delivery services.

This study might give an insight for policy makers regarding the factors affecting institutional delivery service utilization in pastoral community. However, this study was not supported by qualitative methods. The findings of this study might be subjected to social desirability bias because the respondents were interviewed by health professionals. Furthermore, women might experience recall bias, particularly on the services they had got during their previous obstetrics such as during ANC visit.

\section{Conclusions}

The study showed that institutional delivery service in the study area was low. Mothers resided $1 \mathrm{~h}$ or less far from health facilities, attending ANC, previous history of still birth, having good knowledge on pregnancy and child birth, and husband involved during decision making on institutional delivery were factors associated with institutional delivery service utilization. Therefore, strengthen ANC services, awareness creation provision at the community level, and constructing health facilities to the nearby the residents of the community could improve institutional delivery service utilization.

\section{Abbreviations}

ANC: Antenatal Care; EDHS: Ethiopia Demographic and Health Survey;

EMDHS: Ethiopia Mini Demographic and Health Survey; HIV: Human Immune Virus; MMR: Maternal Mortality Ratio; TTBAs: Trained Traditional Birth

Attendants; WHO: World Health Organization

\section{Acknowledgements}

Authors would like to thank all respondents for their willingness to participated in the study. We are also grateful to Afar Regional Health Bureau, Dubti District Health Office, and Samara University for material support. Finally, our appreciation goes to data collectors for their unreserved contribution in data collection activities.

\section{Authors' contributions}

WS conceived the study, developed the tool, coordinated the data collection activity, and carried out the statistical analysis. AB participated in the design of the study, development of the tool, and drafting of the manuscript. AD and TG participated in the design of the study and development of the tool, performed statistical analysis and drafted the manuscript. All authors read and approved the final manuscript.

\section{Authors' information}

WS is Master of Public Health (MPH) and working in Afar Regional Health Bureau as Family Health Coordinator, Samara, Ethiopia. AB is an Associate Professor of Public Health in Reproductive Health and working as a lecturer in the Department of Epidemiology and Biostatistics, College of Medicine and Health Sciences, Mekelle University, Ethiopia. AD is an Assistant professor 
of Health Service Management and working in the Department of Health Systems and Policy, Institute of Public Health, College of Medicine and Health Sciences, University of Gondar, Ethiopia, and TG is MSc and working as a lecturer in the Department of Health Systems and Policy, Institute of Public Health, College of Medicine and Health Sciences, University of Gondar, Ethiopia.

\section{Funding}

This study was funded by self (Principal investigator).

\section{Availability of data and materials}

Data will be available upon reasonable request from the corresponding author.

\section{Ethics approval and consent to participate}

Ethical approval was obtained from Samara University Ethical Review Committee. Permission letter was also obtained from Afar regional health bureau. Official letter of co-operation was obtained from Dubti district health office. Respondents were briefed about the purpose and objectives of the study. Participant's privacy and confidentiality of the information were maintained. Verbal consent was obtained from each participant and from their parents/guardians for those mothers whose age less than 18 years to ensure their voluntariness to participate in the study and all participants had a right to withdraw at any time or to skip for a single question or segment of questions she did not want to answer or refuse to participate at all with no negative repercussion.

\section{Consent for publication}

Not applicable.

\section{Competing interests}

The authors declare that they have no competing interests.

\section{Author details}

${ }^{1}$ Family Health Coordinator, Afar Regional Health Bureau, Afar, Ethiopia.

${ }^{2}$ Department of Epidemiology and Biostatistics, Mekelle University, Mekelle, Ethiopia. ${ }^{3}$ Department of Health Systems and Policy, Institute of Public Health, College of Medicine and Health Sciences, University of Gondar, Po. Box: 196, Gondar, Ethiopia.

Received: 29 August 2018 Accepted: 28 July 2019

Published online: 13 August 2019

\section{References}

1. WHO. The World Health Report 2005: Make every mother and child count World Health Organization; 2005. https://www.who.int/whr/2005/en/.

2. Bhutta ZA, Black RE. Global maternal, newborn, and child health-so near and yet so far. N Engl J Med. 2013;369:2226-35.

3. Khan KS, Wojdyla D, Say L, Gülmezoglu AM, Van Look PF. WHO analysis of causes of maternal death: a systematic review. Lancet. 2006:367:1066-74.

4. Peipert JF, Madden T, Allsworth JE, Secura GM. Preventing unintended pregnancies by providing no-cost contraception. Obstet Gynecol. 2012 120:1291.

5. Organization WH. Maternal mortality fact sheet. Geneva: World Health Organization; 2010

6. Federal Democratic Republic of Ethiopia Ministry of Health. National Reproductive Health Strategy 2006-2015. 2005. https://www.phe-ethiopia. org/admin/attachment-161-National_RH.

7. [Ethiopia] CSAC. Ethiopian Demographic and Health Survey 2011. Addis Ababa, Ethiopia. 2012

8. [Ethiopia] CSAC. Ethiopia Mini Demographic and Health Survey 2014. Addis Ababa, 2014.

9. Mekonnen MG, Yalew KN, Umer JY, Melese M. Determinants of delivery practices among Afar pastoralists of Ethiopia. The Pan African medical journal. 2012;13:17

10. Hagos S, Shaweno D, Assegid M, Mekonnen A, Afework MF, Ahmed S. Utilization of institutional delivery service at Wukro and Butajera districts in the northern and south Central Ethiopia. BMC Pregnancy Childbirth. 2014;14:178.
11. Amano A, Gebeyehu A, Birhanu Z. Institutional delivery service utilization in Munisa Woreda, south East Ethiopia: a community based cross-sectional study. BMC Pregnancy Childbirth. 2012;12:105.

12. Exavery A, Kanté AM, Njozi M, Tani K, Doctor HV, Hingora A, et al. Access to institutional delivery care and reasons for home delivery in three districts of Tanzania. Int J Equity Health. 2014;13:48.

13. Abeje G, Azage M, Setegn T. Factors associated with institutional delivery service utilization among mothers in Bahir Dar City administration, Amhara region: a community based cross sectional study. Reprod Health. 2014;11:22

14. Teferra AS, Alemu FM, Woldeyohannes SM. Institutional delivery service utilization and associated factors among mothers who gave birth in the last 12 months in Sekela District, north west of Ethiopia: a community-based cross sectional study. BMC Pregnancy Childbirth. 2012;12:74.

15. Esena RK, Sappor M-M. Factors associated with the utilization of skilled delivery services in the Ga east municipality of Ghana part 2: barriers to skilled delivery. Int J Sci Tech Res. 2013;2:195-207.

16. Kidanu S, Degu G, Tiruye TY. Factors influencing institutional delivery service utilization in Dembecha district, Northwest Ethiopia: a community based cross sectional study. Reprod Health. 2017;14:98.

17. Fikre AA, Demissie M. Prevalence of institutional delivery and associated factors in Dodota Woreda (district), Oromia regional state, Ethiopia. Reprod Health. 2012:9:33.

18. Agency CS. Mini Ethiopian demographic and health survey; 2014.

19. [Ethiopia] CSAC. Ethiopia Demographic and Health Survey 2016. Addis Ababa, Ethiopia. 2016.

20. El Shiekh B, van der Kwaak A. Factors influencing the utilization of maternal health care services by nomads in Sudan. Pastoralism. 2015;5:23.

21. Worku AG, Yalew AW, Afework MF. Factors affecting utilization of skilled maternal care in Northwest Ethiopia: a multilevel analysis. BMC Int Health Hum Rights. 2013;13:20.

22. Odo D, Shifti D. Institutional delivery service utilization and associated factors among child bearing age women in Goba Woreda, Ethiopia. J Gynecol Obstet. 2014:2:63-70.

23. Feyissa TR, Genemo GA. Determinants of institutional delivery among childbearing age women in Western Ethiopia, 2013: unmatched case control study. PLoS One. 2014;9:e97194

\section{Publisher's Note}

Springer Nature remains neutral with regard to jurisdictional claims in published maps and institutional affiliations.

\section{Ready to submit your research? Choose BMC and benefit from:}

- fast, convenient online submission

- thorough peer review by experienced researchers in your field

- rapid publication on acceptance

- support for research data, including large and complex data types

- gold Open Access which fosters wider collaboration and increased citations

- maximum visibility for your research: over $100 \mathrm{M}$ website views per year

At BMC, research is always in progress.

Learn more biomedcentral.com/submissions 